\title{
Phase Constituents and Compressive Yield Stress of Ni-Co Base Alloys
}

\author{
C. Y. Cui*, Y. F. Gu, D. H. Ping, T. Fukuda and H. Harada \\ High Temperature Materials Center, National Institute for Materials Science, Tsukuba 305-0047, Japan
}

Phase constituents and compressive yield stress of Ni-Co base alloys have been investigated. The results showed that two-phases of $\gamma$ and $\gamma^{\prime}$ were the main constituents in all the alloys. $\mathrm{Ni}_{3}$ Ti-type $(\eta)$ phase was observed in the alloys with lower Co and Ti content (alloy20); while a new intermetallic $(\mathrm{Ni}, \mathrm{Co}, \mathrm{Cr})_{3}(\mathrm{Ti}, \mathrm{Al})$ phase with a hexagonal structure was detected in the higher $\mathrm{Co}$ and $\mathrm{Ti}$ containing alloy(alloy50). At temperatures lower than $1023 \mathrm{~K}$, the compressive yield stress increased with increasing Co content up to 28.6 mass \% and Ti content up to 7.4 mass \%, but decreased with more Co and Ti addition. At temperatures higher than $1273 \mathrm{~K}$, all the alloys showed similar yield stress. [doi:10.2320/matertrans.MBW200703]

(Received October 16, 2007; Accepted November 21, 2007; Published January 10, 2008)

Keywords: nickel-cobalt alloys, phase constituents; yield stress

\section{Introduction}

Recently, Ni-Co base alloys, termed as TMW alloys, have been developed for turbine disk applications. ${ }^{1,2)}$ In this alloy system, it contains about 20 31 mass\% Co, 5.0 7.4 mass\% $\mathrm{Ti}, 12 \sim 16$ mass $\%$ Cr, 1.5 2.5 mass\% Al, 2 3 mass\% Mo, $1 \sim 1.3$ mass $\% \mathrm{~W}$, Ni balance. The contents of Co and Ti are actually higher than those in commercially used disk alloys, such as 15 mass \% Co and 5 mass\% Ti in U720LI (developed by Special Metals Corporation), ${ }^{3)} 18.5$ mass\% Co and 3.6 mass\% Ti in RR1000(developed by Rolls-Royce Corporation). ${ }^{4)}$ It is known that $\mathrm{Ni}_{3} \mathrm{Ti}(\eta)$ phase with a hexagonal close packed (hcp) structure forms easily in Ni-base superalloy with high Ti content. ${ }^{5)}$ Although TMW alloys contain higher amount of Ti than U720LI and RR1000, some of TMW alloys are only composed of $\gamma$ and $\gamma^{\prime}$ two phases. Also, TMW alloys exhibit improved phase stability, superior tensile strength up to $1023 \mathrm{~K}$ and higher creep resistance up to $998 \mathrm{~K}$ than those of the U720LI. ${ }^{2,6)}$ On the other hand, $\mathrm{Ni}_{3} \mathrm{Ti}(\eta)$ phase forms in some of TMW alloy with high Ti content. ${ }^{6}$ ) The $\eta$ phase is generally considered to have a deleterious effect on alloy's ductility. ${ }^{7)}$

It has been suggested that the formation of $\eta$ phase can be restrained by more Co addition. ${ }^{8)}$ Up to now, the maximum Co and Ti contents in TMW alloys are 31 mass $\%$ and 7.4 mass $\%$, respectively. It is still unknown whether the $\eta$ phase exists or any other compounds would form in higher $\mathrm{Co}$ and Ti containing alloys. Thus, this paper investigates the phase constituents and compressive yield stress of new Ni-Co base alloys with higher Co and Ti.

\section{Experimental}

Table 1 lists the nominal chemical composition of the alloys investigated in present study. The base alloys, U720LI and Co-16.9 mass\% Ti, were first cast. The alloys were prepared by mixing the above two base alloys in proportion as listed in Table 1. The heat treatment was carried out in a similar manner to U720LI, which is $1373 \mathrm{~K} / 7200 \mathrm{~s}$ water quenching (WQ) followed by $923 \mathrm{~K} / 86400 \mathrm{~s}$ and $1033 \mathrm{~K} /$

*Corresponding author, E-mail: Cui.Chuanyong@nims.go.jp
57600 s air cooling (AC). For microstructural observations, the samples were etched in a solution of kalling reagent $\left(100 \mathrm{mlHCl}, 100 \mathrm{ml}\right.$ methanol and $\left.50 \mathrm{~g} \mathrm{CuCl}_{2}\right)$. The microstructures were then observed by using a scanning electron microscope (SEM). The phase constituents were determined by X-ray diffraction (XRD) under $40 \mathrm{kV}$ and $300 \mathrm{~mA}$ and differential thermal analysis (DTA). The thin foils for transmission electron microscope (TEM) observations were prepared by a twin-jet electron polisher in a chemical solution of $23 \%$ perchloric acid and $77 \%$ acetic acid at about $233 \mathrm{~K}$ and then examined using a Philips CM200 operated at $200 \mathrm{kV}$.

Compressive specimens with $3 \mathrm{~mm}$ in diameter and $6 \mathrm{~mm}$ in height were cut by an electric discharge machining (EDM) from the heat-treated samples. Compressive tests were performed at a nominal strain rate of $2.5 \times 10^{-4} \mathrm{~s}^{-1}$ on a SHIMADZU AG50KNI testing machine in a vacuum from room temperature to $1423 \mathrm{~K}$.

\section{Results and Discussion}

A typical DTA thermogram up to $1673 \mathrm{~K}$ obtained at a heating rate of $0.17 \mathrm{~K} / \mathrm{s}$ is shown in Fig. 1. Only one exothermic peak at $1609 \mathrm{~K}$ in alloy0 (U720LI) and $1453 \mathrm{~K}$ in alloy100 (Co-16.9 mass\%Ti) was observed, which corresponds to the alloy's melting temperature. While in alloy20 with 20 mass $\%$ Co-16.9 mass\% Ti addition, alloy50 with 50 mass $\%$ Co-16.9 mass\% Ti addition and alloy70 with 70 mass $\%$ Co- 16.9 mass $\% \mathrm{Ti}$ addition, two exothermic peaks appeared at the heating curves, one at higher temperature was the melting temperature and another at lower temperature was believed to be associated with the melting of other phases, which will be identified in the following microstructural analysis. In addition, the DTA results also showed that the melting temperature of the alloys decreased with increasing $\mathrm{Co}$ and $\mathrm{Ti}$ content, indicating that the Co16.9 mass $\% \mathrm{Ti}$ addition can reduce the melting temperature.

Figure 2 shows the XRD pattern of the alloys. A similar curve was observed in alloy0, alloy70 and alloy100, those diffraction peaks can be identified as $\gamma$ and $\gamma^{\prime}$ phases. However, extra peaks as indicated by arrows in alloy 20 were detected, and those peaks can be indexed as the (201) and 
Table 1 Chemical composition of the Ni-Co base alloys made by mixing U720LI with Co-16.9 mass\% Ti (mass\%).

\begin{tabular}{|c|c|c|c|c|c|c|c|c|c|c|c|}
\hline Alloy & $\begin{array}{c}\text { U720LI/ } \\
\text { Co-Ti }\end{array}$ & $\mathrm{Cr}$ & $\mathrm{Co}$ & Mo & W & $\mathrm{Ti}$ & $\mathrm{Al}$ & $\mathrm{C}$ & B & $\mathrm{Zr}$ & $\mathrm{Ni}$ \\
\hline Alloy0 & $100: 0$ & 16.0 & 15.0 & 3.0 & 1.3 & 5.0 & 2.5 & 0.03 & 0.02 & 0.03 & 57.2 \\
\hline Alloy50 & $50: 50$ & 8.0 & 49.1 & 1.5 & 0.6 & 10.9 & 1.3 & 0.01 & 0.01 & 0.02 & 28.6 \\
\hline Alloy70 & $30: 70$ & 4.8 & 62.6 & 0.9 & 0.4 & 13.3 & 0.8 & 0.01 & 0.01 & 0.01 & 17.2 \\
\hline Alloy100 & $0: 100$ & & 83.1 & & & 16.9 & & & & & \\
\hline
\end{tabular}

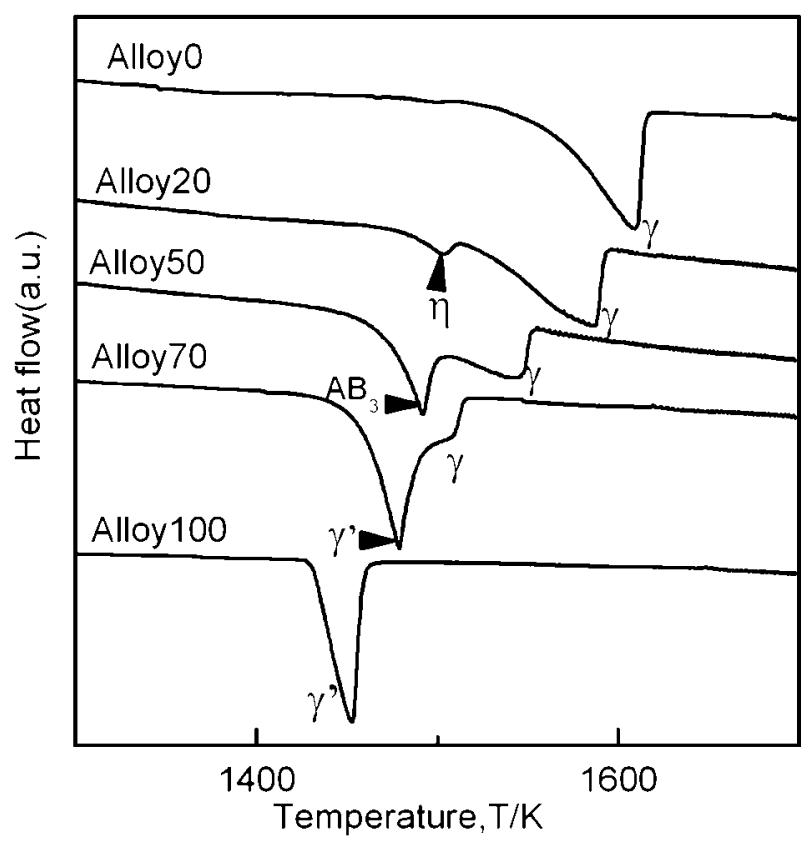

Fig. 1 Typical DTA curves of the Ni-Co base alloys obtained during heating at a rate of $0.17 \mathrm{~K} / \mathrm{s}, \mathrm{AB}_{3}$ represents $(\mathrm{Ni}, \mathrm{Co}, \mathrm{Co})_{3}(\mathrm{Ti}, \mathrm{Al})$ phase.

(212) of $\eta-\mathrm{Ni}_{3} \mathrm{Ti}^{9{ }^{9}}$ In alloy50, extra diffraction peaks marked by arrows were also observed and could not be indexed as $\eta$ $\mathrm{Ni}_{3} \mathrm{Ti}$ or other known phases. In order to identify the new phase, TEM analysis was performed.

The microstructures of the tested alloys are shown in Fig. 3. Alloy0 (U720LI) mainly consisted of $\gamma$ and $\gamma^{\prime}$ phases. The dark particle-like phase was $\gamma^{\prime}$ and the matrix was $\gamma$ phase. The average particle size of $\gamma^{\prime}$ phase was about $0.8 \mu \mathrm{m}$ and the volume fraction of $\gamma^{\prime}$ phase was measured to be about $45 \%$ (Fig. 3(a)). For the alloy20 with 20 mass\%Co-16.9 mass $\% \mathrm{Ti}$ addition, three phases $\left(\gamma, \gamma^{\prime}\right.$ and plate phase) were observed (Fig. 3(b)). The volume fraction was measured to be about $49 \%$ for $\gamma^{\prime}$ and $6 \%$ for the plate phase, respectively. Energy dispersive spectrometer (EDS) analysis showed that there was more Ti content in plate phase than in $\gamma^{\prime}$. The analysis of selected area electron diffraction (SAED) pattern confirmed that the plate phase is a $\eta-\mathrm{Ni}_{3} \mathrm{Ti}$ phase with a hcp structure $(a=0.509$ and $c=0.832 \mathrm{~nm})$. The diffraction pattern from the [2 $\overline{1} \overline{1} 0$ ] zone axis of the $\eta-\mathrm{Ni}_{3} \mathrm{Ti}$ phase was inserted in Fig. 3(b). Figure 3(c) shows a typical microstructure of the alloy50 with 50 mass\% Co-16.9 mass\% Ti addition, revealing a plate phase with tens of micrometer in length and a high density of cuboidal phase embedded in matrix phase. The SAED patterns of the cuboidal phase revealed a typical $\gamma / \gamma^{\prime}$ diffraction spots from a $[100]_{\gamma}$ zone

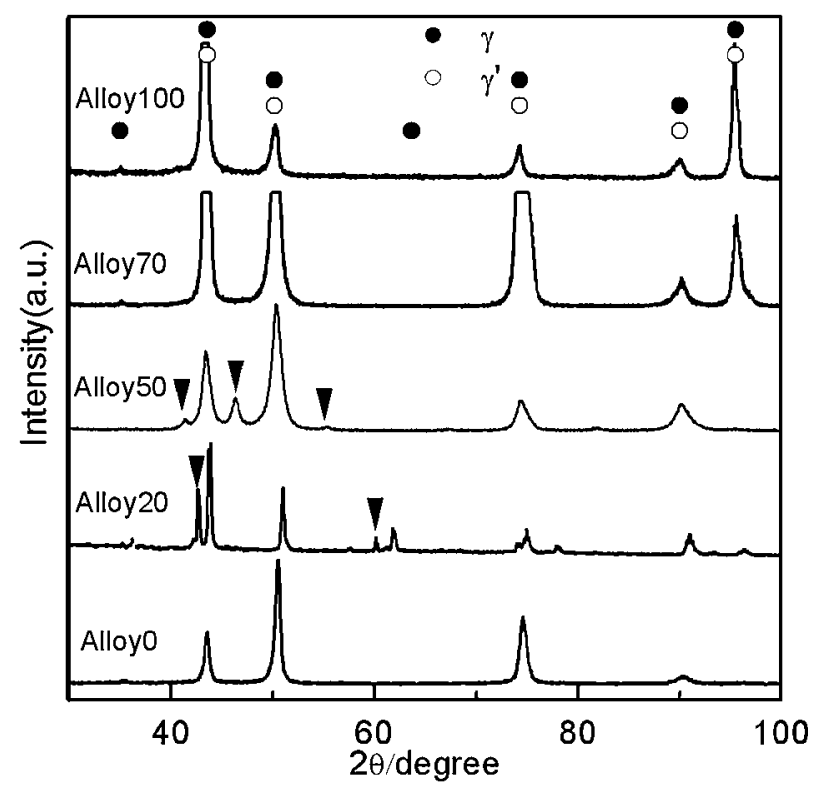

Fig. 2 XRD patterns for the Ni-Co base alloys. Arrows show the extra peaks from phases other than $\gamma$ and $\gamma^{\prime}$.

axis. ${ }^{10)}$ The plate phase was identified to be a $\mathrm{AB}_{3}$-type $(\mathrm{Ni}, \mathrm{Co}, \mathrm{Cr})_{3}(\mathrm{Ti}, \mathrm{Al})$ intermetallic compound with a hexagonal structure $(a=0.51 \mathrm{~nm}$ and $c=1.25 \mathrm{~nm}) .{ }^{11)}$ The plate phase had a higher Ti and lower Al content compared to that of $\gamma^{\prime}$ phase. The total volume fraction of $\gamma^{\prime}$ was estimated to be about $40 \%$ and the plate phase was about $20 \%$. The microstructure of the alloy 70 with 70 mass $\%$ Co- 16.9 mass\% Ti addition only exhibited two phases, which were identified to be $\gamma$ and $\gamma^{\prime}$ phase, based on the XRD pattern. The blocky phase was $\gamma$ and the matrix phase was $\gamma^{\prime}$. The volume fraction of $\gamma$ was estimated to about $30 \%$. Alloy 100 (Co-16.9 mass\% Ti) consisted of $\gamma$ and $\gamma^{\prime}$ phases, which was consistent with Co-Ti binary phase diagram. ${ }^{12)}$ The cuboidal phase was $\gamma$ phase and the matrix phase was $\gamma^{\prime}$. The volume fraction of $\gamma$ was estimated to about $5 \%$.

Based on microstructural observations, two exothermic peaks in Fig. 1 were determined to be $\gamma$ and $\eta$ in alloy20, $\gamma$ and $(\mathrm{Ni}, \mathrm{Co}, \mathrm{Cr})_{3}(\mathrm{Ti}, \mathrm{Al})$ in alloy50, $\gamma$ and $\gamma^{\prime}$ in alloy70, respectively. In alloy20 and alloy50, no exothermic peak from $\gamma^{\prime}$ was detected. This was probably related to the $\gamma^{\prime}$ size and content. It is known that U720LI consists of three types of $\gamma^{\prime}$, that is, primary $\gamma^{\prime}$ with size of $1-10 \mu \mathrm{m}$, secondary $\gamma^{\prime}$ and tertiary $\gamma^{\prime}$ with size smaller than $1 \mu \mathrm{m} .{ }^{3)}$ In order to know the effect of $\gamma^{\prime}$ size on exothermic peak, two samples with and without primary $\gamma^{\prime}$ were obtained by selecting suitable heat treatment. The DTA results showed that exothermic 

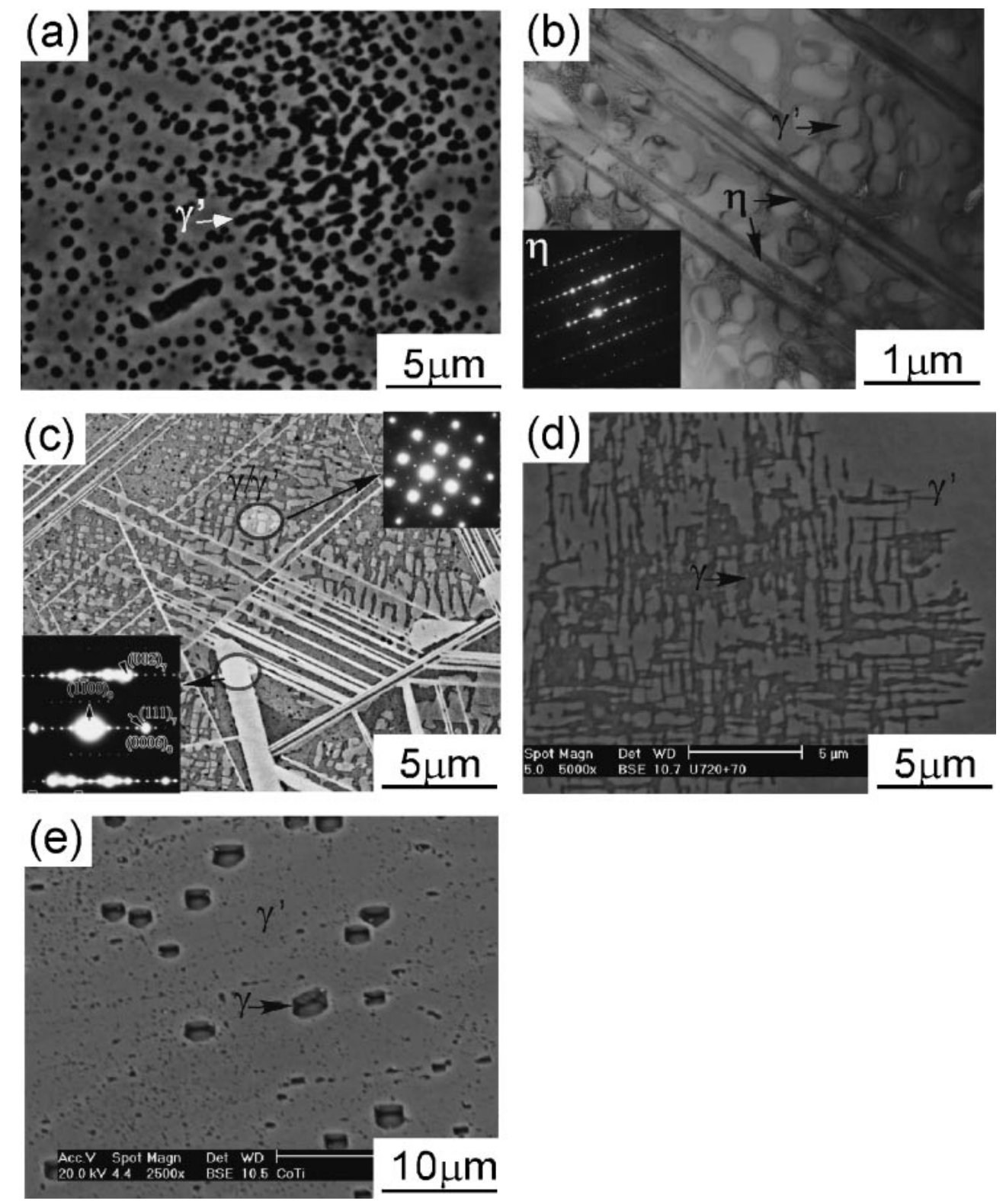

Fig. 3 Typical microstructures of the Ni-Co base alloys after heat treatment at $1373 \mathrm{~K} / 7200 \mathrm{~s}+923 \mathrm{~K} / 86400 \mathrm{~s}$ and $1033 \mathrm{~K} / 57600 \mathrm{~s}$ AC. (a) alloy0 (U720LI); (b) alloy20; (c) alloy50; (d) alloy70 and (e) alloy100 (Co-16.9 mass\%Ti).

peak from $\gamma^{\prime}$ appeared only in the sample with primary $\gamma^{\prime}$, indicating that exothermic peak from $\gamma^{\prime}$ was sensitive to the $\gamma^{\prime}$ size. As shown in Fig. 3, the size of $\gamma^{\prime}$ in alloy20 and alloy50 was about $1 \mu \mathrm{m}$, which was similar to that in alloy0 (U720LI) without $\gamma^{\prime}$ peak during heating, while the size of $\gamma^{\prime}$ in alloy70 was much larger $(>10 \mu \mathrm{m})$. Moreover, the content of $\gamma^{\prime}$ in alloy 20, alloy50 and alloy 70 was $40 \%, 49 \%$ and $70 \%$, respectively.

Figure 4 gives the compressive yield stress of the alloys as a function of temperature. In alloy0, the yield stress decreased with increasing temperature. In alloy20, the yield stresses were higher than those of alloy0, in particular, the yield stress of the alloy 20 dropped very slowly at temperatures below $1023 \mathrm{~K}$. In alloy50, alloy70 and alloy100, anomalous yield behavior was observed, that is, yield stresses increased with increasing temperature, reached the maximum strength at temperature at about $1023 \mathrm{~K}$, and then decreased with increasing temperature. This anomalous yield behavior could be related to the high content of $\mathrm{AB}_{3}$ type intermetallics $\left(60 \%\left(40 \% \gamma^{\prime}+20 \%(\mathrm{Ni}, \mathrm{Co}, \mathrm{Cr})_{3}(\mathrm{Ti}, \mathrm{Al})\right)\right.$ in alloy $50,70 \%$ in alloy70, and $95 \%$ in alloy100), which usually display anomalous yield behavior. ${ }^{5)}$ It is noted that, at temperatures lower than $1023 \mathrm{~K}$, when the Co-16.9 mass\% Ti addition was lower than 20 mass $\%$, the compressive yield stress increased with increasing Co-16.9 mass\% Ti addition. The strength increase was ascribed to the solid-solution strengthening of $\gamma$ and $\gamma^{\prime}$ and precipitate strengthening (higher fraction of $\gamma^{\prime}$ ). ${ }^{1 \text { ) }}$ When the Co-16.9mass\% Ti addition was more than 20 mass $\%$, the strengths decreased with increasing the Co16.9 mass \% Ti addition. The strength drop was related to the decrease of solid solution strengthening and precipitation strengthening. The amount of refractory elements $\mathrm{Cr}, \mathrm{Mo}, \mathrm{W}$ decreased greatly with increasing the Co- 16.9 mass $\%$ addition, as listed in Table 1 . In addition, the $(\mathrm{Ni}, \mathrm{Co}, \mathrm{Cr})_{3}(\mathrm{Ti}, \mathrm{Al})$ 


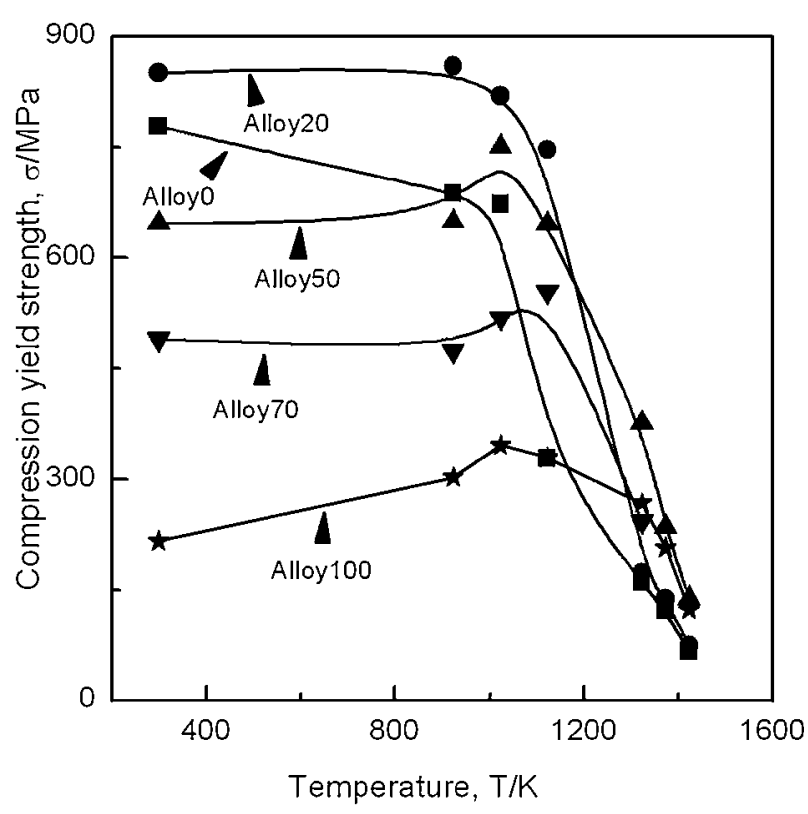

Fig. 4 Compressive yield stress of the Ni-Co base alloys as a function of temperature, the strain rate is $2.5 \times 10^{-4} \mathrm{~s}^{-1}$.

phase also contained high amount of $\mathrm{Cr}$, thus the effect of solid-solution decreased with the increasing of Co-16.9 mass $\% \mathrm{Ti}$ addition. The volume fractions of precipitate phase were $40 \%$ in alloy $50,30 \%$ in alloy 70 and 5\% in alloy 100 , so the effect of precipitate strengthening also decreased with increasing Co-16.9 mass\% Ti addition. At temperature higher than $1273 \mathrm{~K}$, all the alloys showed similar strengths.

According to the binary and Ni-Co-Ti ternary phase diagram, ${ }^{13)}$ as well as the microstructural observations, a partial phase diagram of Ni-Al-Co-Ti is plotted in Fig. 5. Since a fcc $/ \mathrm{L}_{2}$ structure was found in all the tested alloys, the fcc $/ \mathrm{L}_{2}$ structure existed continuously from $\mathrm{Ni}-\mathrm{Al}$ side to Co-Ti side. On the other hand, two three-phase regions existed in the quaternary phase diagram, that is, $\gamma, \gamma^{\prime}$ and $\eta$ existed in the alloys with about 20 mass\% Co-16.9 mass\% Ti addition, and $\gamma, \gamma^{\prime}$ and $(\mathrm{Ni}, \mathrm{Co}, \mathrm{Cr})_{3}(\mathrm{Ti}, \mathrm{Al})$ existed in the alloy with about 50 mass\% Co- 16.9 mass $\%$ Ti addition. Since a $\mathrm{fcc} / \mathrm{L}_{2}$ structure is thought to be a key role for keeping the excellent high-temperature properties for applications, we believe that this partial quaternary phase diagram is helpful for developing new alloys with a fcc $/ \mathrm{L}_{2}$ structure.

\section{Conclusions}

The phase constituents and compressive yield stress of NiCo base alloys have been examined and the following conclusions were drawn:

(1) $\gamma$ and $\gamma^{\prime}$ phases with a fcc $/ \mathrm{L}_{2}$ structure existed continuously from $\mathrm{Ni}$-side to Co-side.

(2) $\eta$ phase formed in alloys with about 28.6 mass $\%$ Co and 7.4 mass $\% \mathrm{Ti}$ content (alloy20), and the $(\mathrm{Ni}$, $\mathrm{Co}, \mathrm{Cr})_{3}(\mathrm{Ti}, \mathrm{Al})$ phase with a hexagonal structure formed

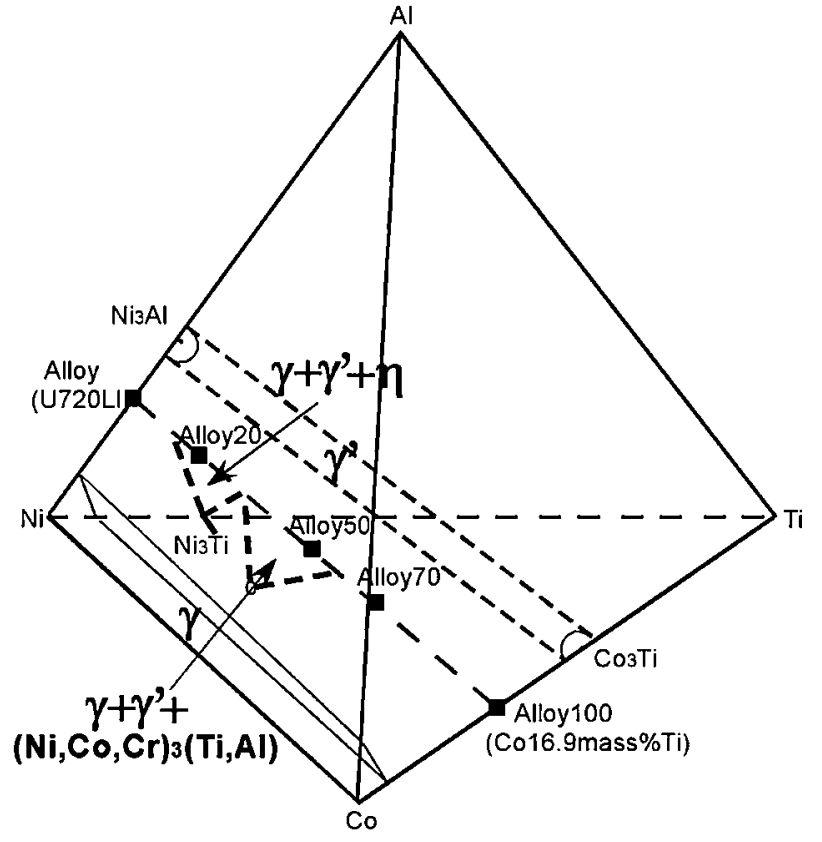

Fig. 5 A partial phase diagram of Ni-Al-Co-Ti quaternary alloy at $1323 \mathrm{~K}$.

in alloys with about 49.1 mass $\%$ Co and 10.9 mass $\% \mathrm{Ti}$ (alloy50).

(3) The compressive yield stress increased with the increasing of Co-16.9 mass\% Ti addition up to 20 mass $\%$, but decreased with more Co-16.9 mass $\% \mathrm{Ti}$ additions at temperatures up to $1023 \mathrm{~K}$.

\section{REFERENCES}

1) C. Y. Cui, Y. F. Gu, H. Harada and A. Sato: Metall. \& Mater. Trans. 36A (2005) 2921-2927.

2) Y. Gu, H. Harada, C. Cui, D. Ping, A. Sato and J. Fujioka: Scripta. Mater. 55 (2006) 815-818.

3) M. P. Jackson and R. C. Reed: Mater. Sci. \& Eng. 259A (1999) 85-97.

4) M. C. Hardy, B. Zirbel, G. Shen and R. Shankar: Superalloy 2004, K. A. Green, T. M. Pollock, H. Harada, T. E. Howson, R. C. Reed, J. J. Schirra and S. Walston, eds. (TMS, Warremda;e, PA, 2004) 83-90.

5) E. W. Ross and C. T. Sims: Superalloy II, C. T. Sims, N. S. Stoloff and W. C. Hagel, eds., (John Wiley \& Sons, New York, NY, 1987).

6) C. Y. Cui, Y. F. Gu, H. Harada, D. H. Ping and A. Sato: Metall. \& Mater. Trans. 37A (2006) 3183-3190.

7) G. K. Bouse: Superalloy 1996, R. D. Kissinger, D. J. Deye, D. L. Anton, A. D. Cetel, M. V. Nathal, T. M. Pollock, and D. A. Woodford, eds., (TMS, Warrendale, PA, 1996) 163-172.

8) C. Y. Cui, Y. F. Gu, D. H. Ping, H. Harada and T. Fukuda: Mater. Sci. \& Enging. (2007), in press.

9) Powder diffraction file, Inorganic phase, International Center for Diffraction Data, 1991.

10) C. Y. Cui, D. H. Ping, Y. F. Gu and H. Harada: Mater. Trans. 47 (2006) 2099-2102.

11) D. H. Ping, C. Y. Cui, Y. F. Gu and H. Harada: Ultramicroscopy. 107 (2007) 791-795.

12) Binary Alloy Phase Diagrams, T. B. Massalski, H. Okamoto, P. R. Subramanian and L. Kacprzak, (1992) p. 1250.

13) K. P. Gupta: J. of. Phase Equilibria. 20 (1999) 65-72. 